\title{
Técnica pessoal para obtenção de enxertos ósseos cranianos
}

\author{
Marco Túlio França ${ }^{1}$, Paulo Sérgio Perri de Carvalho² \\ Hospital Unimed Araçatuba, SP \\ Faculdade de Odontologia da Universidade Estadual Paulista (Unesp), Campus Araçatuba, SP
}

\section{RESUMO}

O objetivo deste artigo foi relatar o desenvolvimento de técnica pessoal para obtenção de enxerto ósseo da calota craniana e divulgá-la entre os neurocirurgiões brasileiros. Essa técnica foi empregada em 101 pacientes que apresentavam necessidade de reconstrução óssea da maxila e/ou da mandíbula. A técnica apresenta o diferencial de determinação da profundidade do crânio por meio de trepanações parciais realizadas na região anterior e posterior do osso parietal para, posteriormente, realizar a remoção do enxerto. Como conclusão, a técnica mostra-se segura e eficiente e pode ser aplicada a qualquer paciente que necessita de cirurgia reconstrutiva.

\section{PALAVRAS-CHAVE}

Enxerto ósseo, crânio.

\begin{abstract}
Personal technique to harvest skull bone grafts

The objective of this paper was to report the development of personal technique to harvest skull bone graft and spread it to Brazilian neurosurgeons. This technique was used in 101 patients who needed reconstructive surgery prior dental implants. The technique presents like differentiate the clinical determination of thickness of cranium prior the osteotomy. This technique, like conclusion, is safe and efficient and can be applied in any reconstructive surgery.
\end{abstract}

\section{KEYWORDS}

Bone graft, skull, bur-holes.

\section{Introdução}

Desde 1929, quando Walter Dandy utilizou pela primeira vez um enxerto ósseo, retirado do osso parietal, para a correção cirúrgica de meningocele intraorbitária, ${ }^{3}$ o crânio tem sido visto como uma fonte doadora de enxertos. Nas últimas décadas, o avanço tecnológico na odontologia tem sido marcante tanto do ponto de vista estético quanto de reabilitação. Hoje, um dos principais recursos disponíveis é a possibilidade da realização de implantes de titânio devolvendo, assim, o elemento dentário, entretanto a atrofia maxilar é o fator limitante para a realização do procedimento e, para isso, faz-se necessária a reconstrução dos enxertos ósseos.

As costelas foram usadas como fonte de enxertos, entretanto altos índices de complicações como pneumotórax (5\% a 30\%) e dor pleurítica persistente (7\%), ${ }^{6,10,11}$ além de camada medular de pobre qualidade, fizeram a técnica ser utilizada apenas em casos selecionados. O ilíaco, outra grande fonte de enxertos para procedimentos diversos, apresenta como principal morbidade a dor pós-operatória, que persiste em média seis semanas, podendo chegar a dois anos em $10 \%$ dos casos. ${ }^{2}$ Mesmo assim, em alguns casos, o ilíaco é utilizado na reconstrução da maxila, por exemplo, quando existe a necessidade de aumentar simultaneamente a altura e a espessura do rebordo alveolar da maxila ou mandíbula.

No entanto, a calota craniana, por sua arquitetura óssea peculiar, baixa incidência de complicações, ausência de dor pós-operatória, além de efeito cosmético excelente em pacientes não calvos, mostra-se como a excelente fonte de enxertos para reconstruir a maxila, permitindo, assim, a colocação dos implantes. ${ }^{1}$

Em 12 de maio de 1993, Kline e Wolfe apresentaram no 72nd Annual Meeting of the American Association of Plastic Surgeons, e publicaram em $1995,{ }^{5}$ sua casuística de 586 casos sem ocorrência de complicações neurológicas. Apresentaram ainda estudo no qual fizeram consulta à outros serviços onde, em 12.672 casos, observaram complicações neurológicas em apenas 3 pacientes. Os autores relataram ainda o conhecimento de outros 8 casos de complicações neurológicas fora destas séries, 4 tem-

1. Neurocirurgião do Hospital Unimed de Araçatuba/SP, presidente do Departamento de Neurocirurgia da Associação Paulista de Medicina.

2. Cirurgião bucomaxilofacial, professor titular da Faculdade de Odontologia de Araçatuba - Universidade Estadual de São Paulo (Unesp) e da Faculdade de Odontologia de Bauru - Universidade de São Paulo (USP). 
porárias e 4 definitivas, cujas cirurgias foram realizadas por cirurgiões com treinamento inadequado.

Strong e Moulthrop ${ }^{9}$ relataram o desenvolvimento de nova técnica para a obtenção de enxerto craniano. É uma modificação da técnica monocortical em que eles utilizam uma serra de Gigli adaptada a um artefato metálico que é conectado à serra oscilatória. Seus resultados mostram que a espessura dos blocos eram de 1,5 a 2,0 $\mathrm{mm}$.

Com relação à qual formação profissional deve ter o cirurgião, Frodel e cols. ${ }^{4}$ e Strong e Moulthrop ${ }^{9}$ lembram que, independentemente da técnica utilizada para obtenção de enxertos do crânio, a experiência e a sensibilidade do cirurgião é fundamental.

Assim, entende-se que está apto a realizar um procedimento aquele profissional que tem treinamento suficiente para executar a técnica, diagnosticar e tratar suas complicações, devendo ser este, nos casos de obtenção de enxerto ósseo do crânio, exclusivamente o neurocirurgião. O procedimento é realizado sob anestesia geral, sendo a intubação nasotraqueal, deixando a cavidade oral livre para o segundo tempo cirúrgico (reconstrução da maxila ou mandíbula), que é realizado pela equipe da cirurgia bucomaxilofacial.

\section{Objetivo}

Difundir, entre os neurocirurgiões brasileiros, técnica cirúrgica pessoal para obtenção de enxertos ósseos da calota craniana aplicada em pacientes que necessitavam de reconstrução óssea da maxila ou mandíbula.

\section{Casuística e método}

Foram operados 101 pacientes entre junho de 1999 e abril de 2011, os quais apresentavam atrofia óssea da maxila e/ou da mandíbula com indicação de implantes dentários. $\mathrm{O}$ procedimento de retirada de enxerto craniano foi realizado por um único neurocirurgião, que acompanhou o pós-operatório avaliando a sintomatologia dolorosa por meio de escala analógica visual com valores de 0 a 10 e complicações pós-operatórias.

\section{Técnica cirúrgica}

A cabeça é lavada com solução degermante de gluconato de clorexidina durante pelo menos 5 minutos; depois, o cabelo é penteado e repartido na região fronto- parietal direita, em uma linha imaginária, paralela à linha média, a qual passa pela apófise orbitária. Pode-se recorrer à utilização de gel capilar e/ou solução de benjoim para manter o cabelo fixado após repartido. É importante fazer isso com a cabeça em posição neutra, a fim de evitar operar sobre a linha média e, com isso, minimizar o risco de lesão do seio sagital superior (Figura 1).

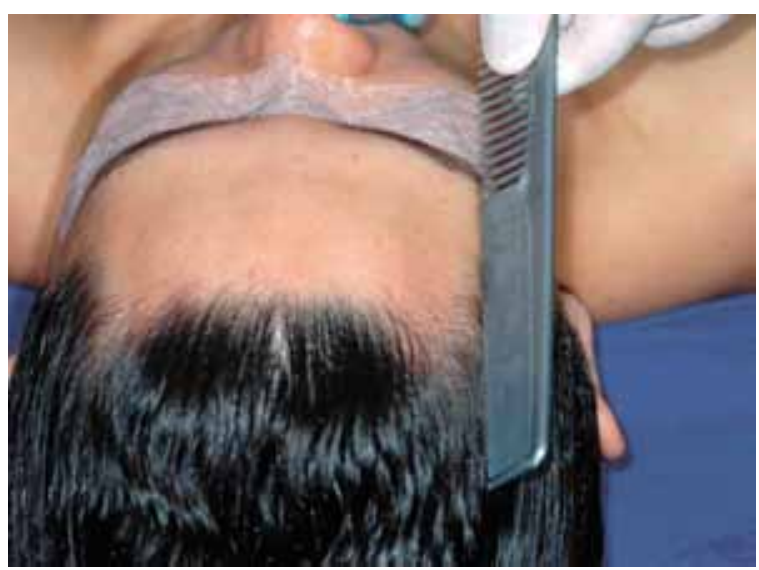

Figura 1 - Cabeça em posição neutra para repartir o cabelo.

Após a divisão do cabelo, inclina-se a cabeça para o lado esquerdo e aplica-se solução aquosa de gluconato de clorexidina, cobrindo o cabelo com compressas, deixando exposta apenas a região da linha de incisão. Em seguida, infiltra-se a região com lidocaína a $2 \%$ com vasoconstrictor, com a finalidade de minimizar a utilização de anestésicos venosos e também o sangramento do tegumento.

Inicia-se a incisão cerca de $2 \mathrm{~cm}$ atrás da linha de implantação capilar e segue-se de maneira linear paralelamente à linha média, sobre a linha de divisão do cabelo previamente preparada, adentrando de maneira simultânea todos os planos anatômicos, ou seja, desde a epiderme até o periósteo.

Com o auxílio de uma rugina, afastam-se os bordos da ferida operatória expondo, assim, a superfície externa de quase todo o osso parietal. Em seguida, são aplicados clipes de Raney, fixando-se um campo cirúrgico sobre os bordos da ferida, promovendo, simultaneamente, a hemostasia e o isolamento dos cabelos; com o auxílio de um afastador autoestático mantém-se a ferida aberta.

O que diferencia a técnica apresentada das demais é que são realizadas duas trepanações, uma em cada ângulo da ferida, iniciando-se pela região anterior do parietal (Figura 2). O pós-oriundo das trepanações (Figura 3) é utilizado para hemostasia do leito doador e também deve ser guardado para utilização do tempo facial. Cabe lembrar que não pode ser utilizada cera óssea enquanto os enxertos não forem totalmente retirados, pois ela prejudica a integração deles. 
A trepanação deve ser realizada de maneira parcial, ou seja, até atingir a díploe (camada medular), deixando íntegra a tábua interna (Figura 4), o que permite avaliar a espessura média do osso parietal, junto aos limites anterior e posterior da área doadora.

O cirurgião deve comparar o comprimento da broca com a profundidade da trepanação. Mantendo-se a referência, são realizadas as osteotomias com motor elétrico de baixa rotação e broca 702, ingressando na tábua externa e na díploe, com especial cuidado em preservar a tábua interna, moldando os enxertos com a forma quadrada ou retangular (Figura 5).

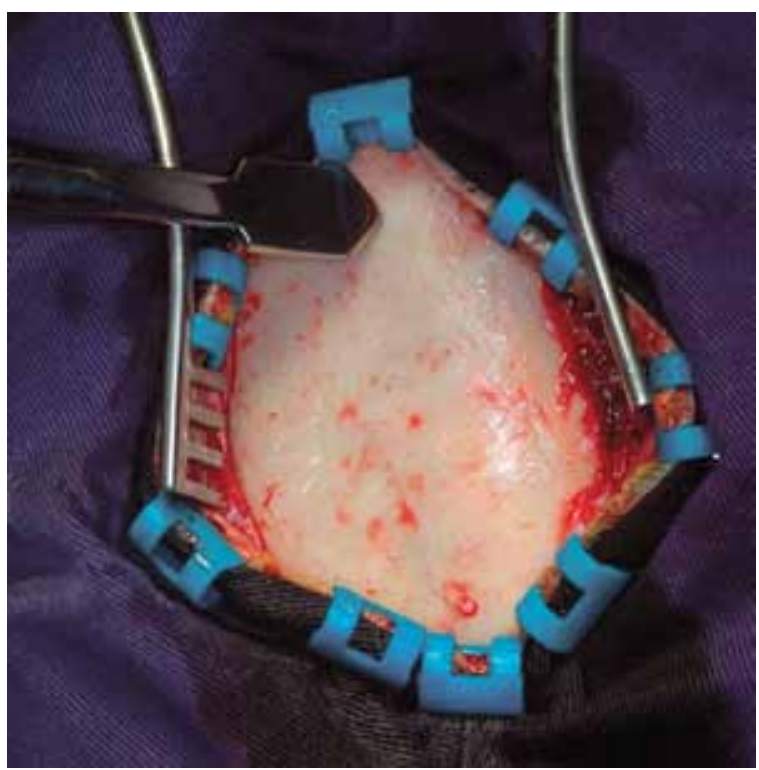

Figura 2 - Posicionamento do trépano cirúrgico na região anterior do osso parietal.

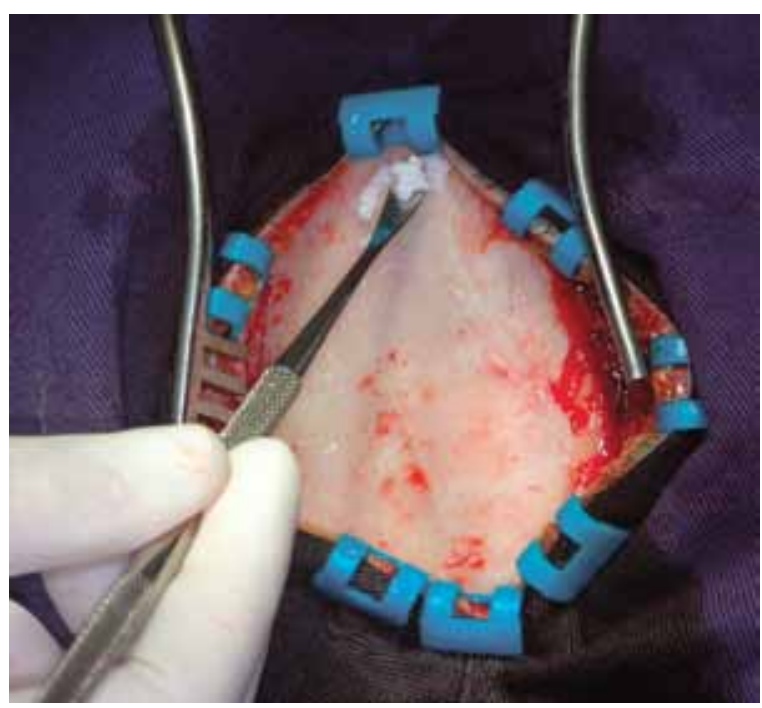

Figura 3 - Coleta do "pó de osso" oriundo da ação do trépano cirúrgico.
Em seguida, a remoção dos blocos é realizada com a ajuda de cinzéis e martelo, de maneira lenta, com golpes de pouco impacto, aplicados em todos os lados e com pequenos movimentos de báscula aplicados aos cinzéis, buscando descolar o enxerto (Figura 6). Broca em forma de roda pode ser utilizada na base dos blocos para facilitar a remoção deles (Figura 7). Finaliza-se com a hemostasia do leito (sendo agora permitida a utilização de cera óssea) e com o arredondamento dos bordos, minimizando a sensação de "degrau", que poderá ser sentido pelo paciente depois de cicatrizada a ferida operatória (Figura 8).

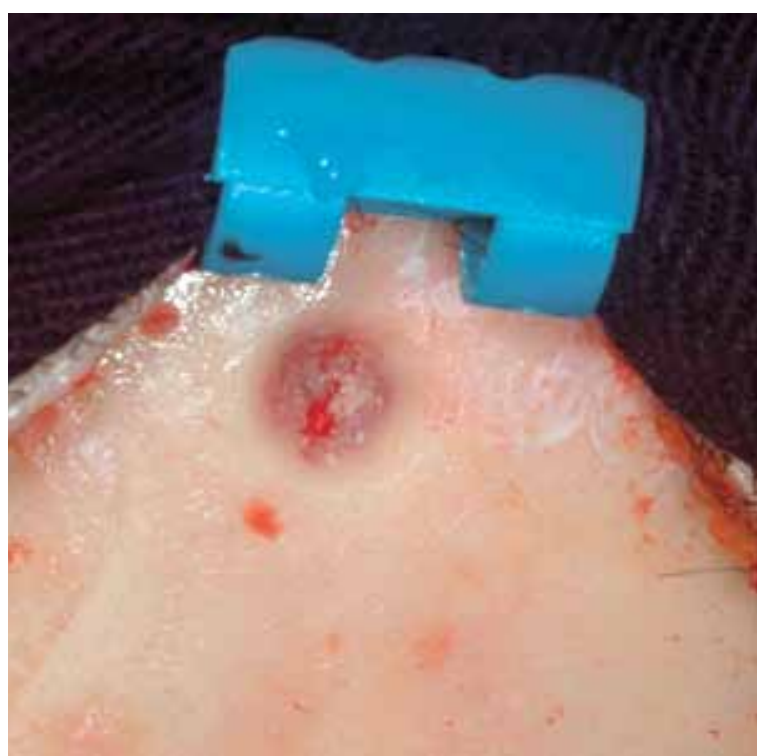

Figura 4 - Cavidade óssea realizada com o trépano cirúrgico determinando a espessura da cortical externa e da díploe (broto de sangue). Ao fundo da cavidade, visualiza-se a cortical interna intacta.

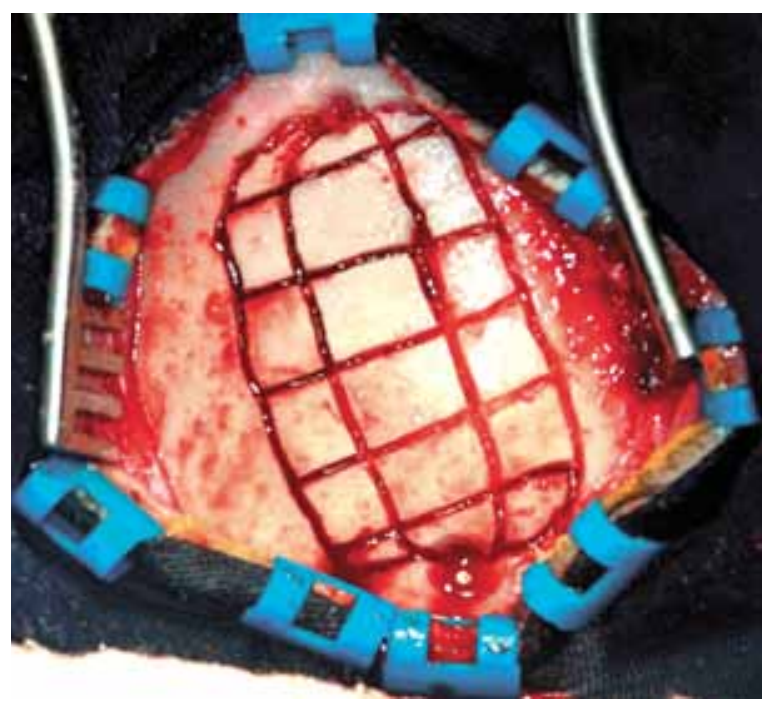

Figura 5 - Divisão dos blocos ósseos a serem removidos. 


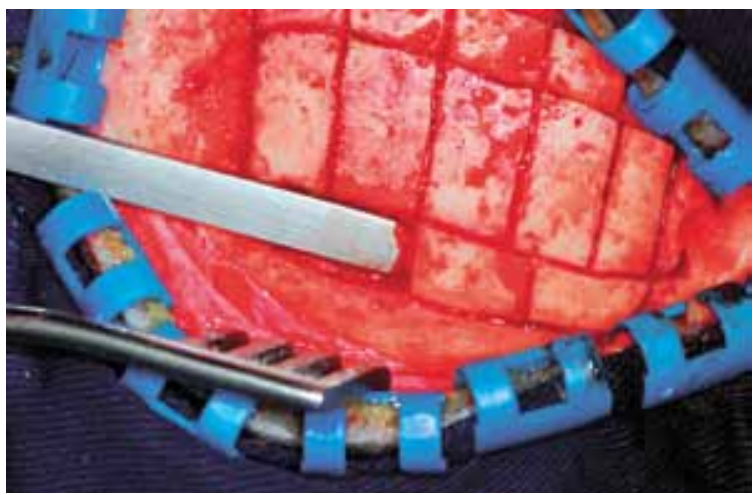

Figura 6 - Remoção do bloco ósseo.

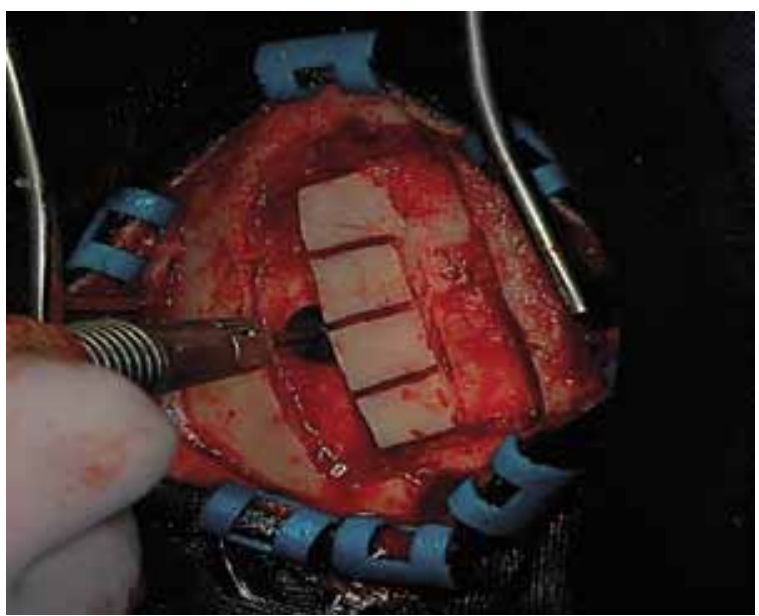

Figura 7 - Aplicação da broca em forma de roda abaixo dos blocos centrais para facilitar a remoção.

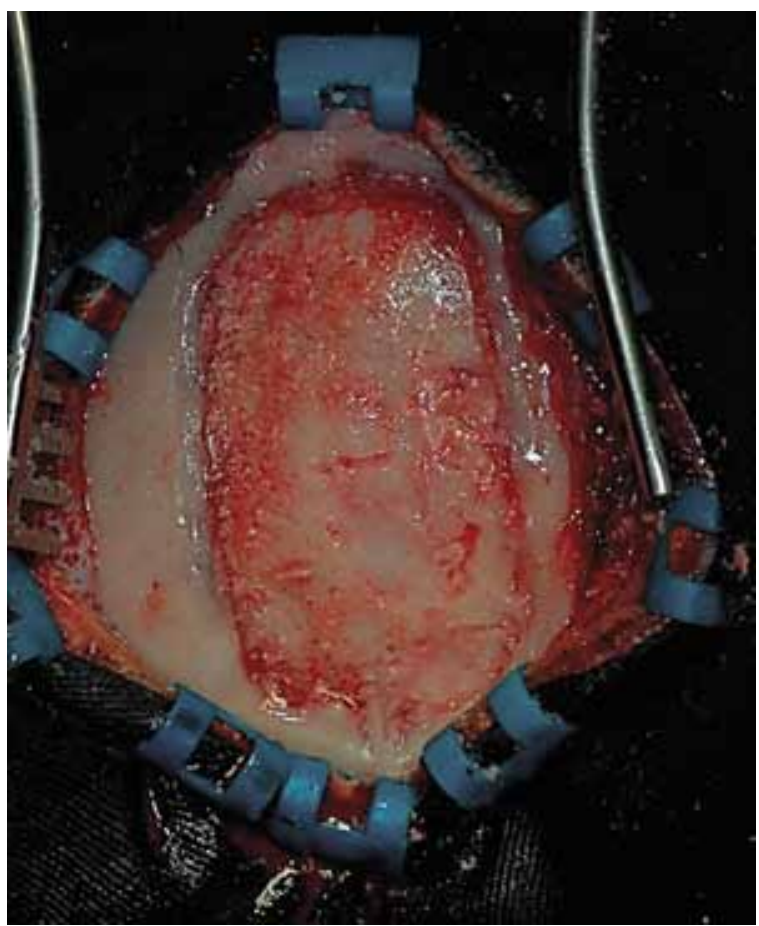

Figura 8 - Hemostasia da área doadora após aplicação da cera óssea.
Não são deixados drenos, e a síntese da ferida é realizada em três etapas, iniciando-se com a sutura de sustentação que abraça o subcutâneo, a gálea aponeurótica e até mesmo o periósteo com fio Vicryl 2-0. A seguir, realiza-se sutura intradérmica com fio de nylon 3-0 buscando o afrontamento dos bordos. Por fim, algumas suturas interrompidas simples de sustentação com fio de nylon 2-0 são aplicadas ao longo da ferida visando minimizar a tensão, facilitando o processo cicatricial. Realizado curativo compressivo, o paciente é entregue à responsabilidade da equipe de cirurgia bucomaxilofacial.

No dia seguinte, é retirado o curativo e o paciente já pode lavar os cabelos. As suturas de sustentação externa, bem como a sutura intradérmica, são removidas após três semanas.

\section{Resultados}

De junho de 1999 até abril de 2011, esse procedimento foi realizado em 101 pacientes, e a sintomatologia dolorosa variou de 0 a 1 no pós-operatório imediato e foi 0 (zero) a partir do segundo dia, sendo controlada, quando necessária, com medicação analgésica (dipirona sódica $500 \mathrm{mg} \mathrm{EV}$ ).

Em nenhum caso houve a ocorrência de complicações neurológicas ou de coleções subgaleais. Em três casos ocorreu infecção da ferida: um deles aplicou tintura de cabelo logo após a retirada das suturas; outro ficou com receio e, apesar de orientado, não lavou a cabeça até o retorno três semanas após; o terceiro teve como diagnóstico epidermólise superficial por reação alérgica à solução de povidine, antisséptico usado na época. Em todos os casos, houve resolução apenas com o uso de antibióticos e curativos. A perda capilar ocorrida por causa da infecção foi completamente recuperada ao longo de seis meses.

\section{Discussão}

A busca de uma técnica segura que possibilitasse a remoção de enxertos ósseos com espessura suficiente e uniforme para as cirurgias reconstrutivas foi o objetivo que motivou o aprimoramento das técnicas divulgadas na literatura e que culminou com o desenvolvimento dessa técnica pessoal.

Para maior segurança do procedimento de obtenção de osso da região parietal, sugere-se que o procedimento seja realizado no lado direito, por ser o hemisfério não dominante na maior parte da população. 
O osso parietal tem, em média, no adulto, 6,80 a 7,72 $\mathrm{mm}$ de espessura, mas pode variar entre 3,0 e $12,0 \mathrm{~mm} .^{7} \mathrm{~A}$ área mais espessa e mais segura para a técnica monocortical de obtenção de enxerto ósseo está entre as linhas média (sutura sagital) e temporal (sutura escamosa), no entanto as osteotomias devem ser afastadas ao menos $2 \mathrm{~cm}$ da linha média para evitar injúria ao seio sagital superior ${ }^{8}$, o que vai ao encontro do descrito nesta técnica no que diz respeito ao preparo do couro cabeludo.

Outro detalhe da técnica e grande diferencial de todas as outras existentes e relatadas na literatura, que propicia segurança durante a osteotomia, é a confecção das trepanações parciais realizadas na região anterior e posterior do osso parietal. Utilizando-se essa técnica, na maioria das vezes, é possível visualizar os limites da cortical externa, camada diploica e cortical interna do crânio. Essa determinação de profundidade permite a retirada de blocos mais espessos (4 a $6 \mathrm{~mm}$ ) do que na técnica demonstrada por Strong e Moulthrop, ${ }^{9}$ cujo enxerto apresentava 1,5 a 2,0 $\mathrm{mm}$ de espessura.

Carvalho e cols. ${ }^{1}$ sugerem que, após a delimitação da área óssea a ser removida, ela seja dividida em blocos, que serão removidos individualmente. Os blocos poderão ser moldados em tamanhos diferentes de acordo com a reconstrução óssea a ser realizada, lembrando que blocos maiores que $1 \times 1 \mathrm{~cm}$ apresentam maior risco de serem fraturados durante a remoção; salienta-se que a aplicação de broca em forma de roda na base deles facilita sua remoção por inteiro.

Com relação à sintomatologia, não houve necessidade de utilizar analgésico de ação central em nenhum caso, e o edema, muito provavelmente pela associação da terapêutica com o curativo compressivo, foi inexpressivo. Os pacientes permanecem internados durante um dia.

Assim, as vantagens que essa técnica apresenta são: segurança, ausência de sintomatologia e edema e curto período de internação hospitalar.

\section{Conclusão}

A técnica apresentada mostrou-se segura e eficiente para a obtenção de enxertos cranianos por ter, como diferencial, a determinação da profundidade do osso parietal por meio de trepanações parciais realizadas nos extremos da área doadora.

\section{Referências}

1. Carvalho PSP, Garcia Jr IR, Bassi APF, França MT. Enxerto de calota craniana na reconstrução de maxilas atróficas. In: Baldacci Filho R, Macedo MCS, editores. Atualização clínica em odontologia. $1^{\text {a }}$ ed. São Paulo: Artes Médicas Divisão Odontológica; 2007. p. 213-27.

2. Cohen M, Figueiroa AA, Haviv $Y$, Schafer ME, Aduss $H$. lliac versus cranial bone for secondary grafting of residual alveolar clefts. Plast Reconstr Surg. 1991;87:423.

3. Dandy WE. An operative treatment for certain cases of meningocele (or encephalocele) into the orbit. Arch Ophtalmology. 1929;2:123.

4. Frodel JL, Marentette LJ, Quatela VC. Calvarial bone graft harvest: technique, considerations, and morbidity. Arch Otolaryngol Head Neck Surg. 1993;119:17-23.

5. Kline Jr RM, Wolfe AS. Complications associated with the harvesting of cranial bone grafts. Plast Reconstr Surg. 1995;95:5.

6. Laurie SW, Kaban LB, Mulliken JB, Murray JE. Donor site morbidity after harvesting rib and iliac bone. Plast Surg. 1984;73:933.

7. Pensler J, MacCarthy JG. The calvarial donor site: an anatomic study in cadavers. Plast Reconstr Surg. 1985;75:648-51.

8. Sheen JH. A change in the site for cranial bone harvesting. Prospect Plast Surg. 1990;5:48-57.

9. Strong EB, Moulthrop T. Calvarial bone graft harvest: a new technique. Otolaryngol Head Neck Surg. 2000;123:547-52.

10. Whitaker LA, Munro IR, Jackson IT. Problems in cranio-facial surgery. J Maxillofac Surg. 1976;4:131.

11. Whitaker LA, Munro IR, Salyer KE. Combined report of problems and complications in 793 craniofacial operations. Plast Reconstr Surg. 1979;64:198.

Endereço para correspondência

Marco Túlio França

Rua Aristides Rocha, 20, Jardim Nova Iorque

16018-485 - Araçatuba, SP

E-mail: mtuliof@hotmail.com 